\title{
The caveolar membrane system in endothelium: From cell signaling to vascular pathology
}

\author{
Antonio Filippini $^{1}$ | Gigliola Sica $^{2}$ | Alessio D'Alessio ${ }^{2}$ (iD
}

${ }^{1}$ Department of Anatomy, Histology, Forensic Medicine and Orthopaedics, Unit of Histology and Medical Embryology, Sapienza University of Rome, Rome, Italy

2 Istituto di Istologia ed Embriologia, Università Cattolica del Sacro Cuore, Rome, Italy

\section{Correspondence}

Alessio D'Alessio, PhD, Istituto di Istologia ed Embriologia, Università Cattolica del Sacro Cuore, Largo Francesco Vito 100168 Roma, Italia.

Email: alessio.dalessio@unicatt.it

Funding information

Fondi di Ateneo Linea D.1., 2017, Università Cattolica del Sacro Cuore, Grant number: R4124500601

\begin{abstract}
Caveolae are 50- to 100-nm cholesterol and glycosphingolipid-rich flask-shaped invaginations commonly observed in many terminally differentiated cells. These organelles have been described in many cell types and are particularly abundant in endothelial cells, where they have been involved in the regulation of certain signaling pathways. Specific scaffolding proteins termed caveolins, along with the more recently discovered members of the cavin family, represent the major protein components during caveolae biogenesis. In addition, multiple studies aimed to investigate the expression and the regulation of these proteins significantly contributed to elucidate the role of caveolae and caveolins in endothelial cell physiology and disease. The aim of this review is to survey recent evidence of the involvement of the caveolar network in endothelial cell biology and endothelial cell dysfunction.
\end{abstract}

\section{KEYWORDS}

angiogenesis, cancer, caveolae, caveolin, endothelial cells, EPCs

\section{1 | INTRODUCTION}

Lipid rafts (LRs) and caveolae are distinct plasma membrane microdomains with a unique lipid composition present in a variety of different cell types. Unlike LRs, whose existence remains elusive in living cells, caveolae are $50-100 \mathrm{~nm}$ flask-shaped invaginations clearly detectable by electron microscope. During the last two decades both LRs and caveolae have been involved in a variety of biological processes including cell growth, proliferation, apoptosis, angiogenesis, and cancer. The shape as well as the biogenesis of caveolae depend mostly on the presence of small scaffolding proteins belonging to the caveolin gene family that includes caveolin-1, caveolin-2, and caveolin-3. These scaffolding proteins contribute to the assembly of a complex molecular platform that facilitates the integration of a variety of signaling molecules as well as the regulation of certain transmembrane signaling events. In addition, the presence of caveolin represents a useful molecular marker for the isolation of caveolae-enriched membranes from cells cultivated in vitro, that is central for the investigation of the role of these organelles in cellular functions both in physiological and pathological conditions. In this review, we mainly focus on recent findings that support the role of caveolae and caveolin proteins in the regulation of endothelial cells (EC) functions, with emphasis on potential application in angiogenic-based therapy.

\section{2 | BIOGENESIS OF LIPID RAFTS AND CAVEOLAE}

Our view of the "fluid mosaic" model of the plasma membrane illustrated more than 40 years ago, that describes 
the cell surface as a low energy structure with randomly dispersed molecules, ${ }^{1}$ has been deeply revised through the years. Starting from the late $80 \mathrm{~s}$ an increasing number of evidence have revealed the existence of specific plasma membrane domains particularly enriched in glycosphingolipids, gangliosides, and cholesterol termed LRs, that have soon revealed an interesting talent to sequestrate a variety of structural and signaling molecules, leading to a fine regulation of downstream mechanisms in different cell types. ${ }^{2-6}$ LRs are detergent-resistant non invaginated, flat, plasma membrane microdomains containing a unique combination of glycosphingolipids, and cholesterol. ${ }^{7,8}$ Two main types of LRs are described based on the presence of the cholesterol binding protein caveolin-1. ${ }^{9}$ LRs that contain caveolin-1 can promote the formation of clearly detectable flask-like invaginations termed caveolae. In contrast, LRs that do not contain caveolin-1 remain as presumably flat undetectable structures on the plasma membrane. However, in certain cell types such as neurons and lymphocytes, the presence of LRs along with the expression of caveolin-1 do not result in the formation of caveolae, raising the question about the function of caveolin-1 in these cell types. ${ }^{10}$ Caveolae were initially described in the early 50s by Palade and Yamada as omega-shaped membrane invaginated "smooth" (noncoated) vesicles of $50-100 \mathrm{~nm}$ in size. ${ }^{11,12}$ After their discovery, caveolae have been identified in a variety of cell types, including smooth muscle cells, EC, fibroblasts and adipocytes, challenging many investigators to explore their functional significance in cell functions. Early studies, almost exclusively based on morphological observation, reinforced the earliest hypothesis, anticipated by Palade of caveolae as structures involved almost exclusively in transcellular trafficking of molecules across the EC barrier. ${ }^{13}$ Other well-known functions of caveolae include cholesterol transport, ${ }^{14,15}$ potocytosis, ${ }^{16}$ and endocytosis. ${ }^{17}$ Structurally, caveolae display different level of organization, forming grape-like clusters, rosettes, membrane-bound or detached vesicles and tubule-like structures, clearly detectable by electron microscope in different cell types. ${ }^{18}$ However, only with the discovery of the involvement of caveolae in the sequestration and uptake of small molecules ${ }^{16}$ and later with the identification of caveolin-1. ${ }^{19-21}$ as the first molecular marker used as a convenient tool for the isolation of caveolaeenriched membranes, ${ }^{22-26}$ the research in this field has greatly boosted. Caveolin-1 was the first member of this family to be identified, ${ }^{19}$ followed by the discovery of caveolin- $2^{27}$ and caveolin-3. ${ }^{28}$ Caveolin-1 is expressed in most cell types such as adipocytes, epithelial cells, and fibroblasts where it is typically found co-expressed with caveolin-2. ${ }^{27,29}$ Caveolin3 , which appears shorter but functionally and structurally similar to caveolin-1, is known to be muscle specific and expressed in skeletal, cardiac and smooth muscle cells. ${ }^{28}$ Unlike caveolin-1 and caveolin-3, caveolin-2 appears incapable of forming caveolae and is usually found sequestered and degraded in the Golgi apparatus in the absence of caveolin- $1 .^{27,30,31}$ Caveolins contain three distinct regions including a cytosolic $\mathrm{N}$-terminal domain, a transmembrane domain and a hydrophilic C-terminal domain. Although the C-terminal domain has been demonstrated to be a site of palmitoylation, the significance of this modification is debated ${ }^{32-34}$ and this modification seems not essential for proper localization of caveolins into caveolae. While the contribution of caveolin- 1 is crucial for the formation of caveolae, recent studies identified a novel family of proteins termed cavins that actively participate to the biogenesis of caveolae, and specifically contribute to membrane curvature of these organelles. ${ }^{35}$ Therefore, the persistence of caveolin and cavin oligomers is essential for the stability of plasma membrane bound caveolae. However, this association can be modulated by a variety of stimuli that destabilize caveolae and usually terminate with internalization of the caveolin proteins. Four different cavin proteins have been identified so far with different cellular distribution. Cavin 1/Polymerase I and transcript release factor (PFTR/Cav60/Cavin) appears to show an overlapping expression pattern with caveolin-1 and is a key molecule for caveolae biogenesis. ${ }^{36,37}$ Cavin 2, encoded by the Serum Deprivation Response (SDPR) gene, cavin-3 (PRKCDBP) and the muscle-specific cavin 4 (MURC) are all also involved in the formation of caveolae. ${ }^{38-40}$ An additional molecule, termed EHD2 belonging to the Eps15 homology domain (EHD) proteins, appears to be specifically involved in the regulation of membrane dynamics. ${ }^{41,42}$ To this regard, it has been recently demonstrated that due to its ability to change its structural conformation in the presence of ATP, EHD2 can switch from an active membrane-bound conformation to an inactive soluble form, regulating caveolae association to the plasma membrane. ${ }^{43}$ Hence, the caveolar network represents undoubtedly a molecular platform that has been stimulating the interest of many investigators for years in seeking of the physiological and pathological significance of these organelles in many fields of research, from membrane biogenesis to diseases.

\section{3 | THE CONTRIBUTION OF THE CAVEOLAR NETWORK TO CELL SIGNALING}

There is increasing evidence that demonstrate the involvement of the caveolar network in cell responses to incoming chemical and mechanical stimuli as well as in the regulation of the downstream signal transduction cascades. The caveolar network can function as a molecular switch that can activate, inhibit or modulate specific cellular functions in a variety of cell types depending on the precise interactions occurring 
between signaling molecules within the organelle itself. With the discovery of the caveolin gene family, many evidence have been collected on the involvement of caveolae and caveolin proteins in cell signaling. ${ }^{44-47}$ It has been demonstrated that mice carrying a single deletion of any of the caveolin genes resulted vital and fertile, whereas the double knock-out of caveolin-1 and -3 developed severe cardiomyopathy and inflammation, ${ }^{48}$ raising interest on the pathological role of these organelles. On the other hand, the role of caveolin-2 in this scenario is less clear and the protein appears to play a regulatory role for caveolae stability. ${ }^{49}$ Therefore, the information concerning the involvement of caveolins in signal transduction mostly come from studies carried out on caveolin-1 and have focused to investigate how the proficiency of this protein to bind and sequestrate a variety of signaling adapters can regulate downstream pathways. This scaffolding talent of caveolin-1 led to the concept of the "caveolae signaling hypothesis" 23 that predicts the existence of interactions between the 20-amino acid segment in the caveolin scaffolding domain (CSD, aa 82-101) ${ }^{50}$ and an aromatic-rich caveolin binding motif (CBM) on associated signaling partners. ${ }^{51}$ Binding to CSD is sufficient to inhibit the activity of many signaling molecules such as G-proteins, Src-like kinases, eNOS, H-Ras, and EGFR. ${ }^{52-54}$ In vivo studies supported the idea that caveolins can modulate signal transduction independently of their structural role carried out during caveolae formation, ${ }^{55}$ encouraging many groups to investigate more in deep the contribution of caveolins to specific cellular mechanisms. Different types of membrane bound and intracellular receptors involved in signal transduction, such as G protein-coupled receptors (GPCRs) and receptor tyrosine kinases (RTKs), have been found localized into caveolae or to interact with caveolins within the endothelial compartment. ${ }^{56}$ Some GPCRs appear more dependent on the integrity of LRs whereas other members of the family have been found to interact with caveolins, suggesting that caveolar platform as well as LR microdomains contribute to their function. CCR5 is a chemokine receptor belonging to GPCRs family involved in the modulation of immune response triggered by chemokines. The contribution of functional LR microdomains to proper activation of CCR5 signaling has been demonstrated by the use of cholesterol depleting agents such as hydroxypropyl- $\beta$ cyclodextrin, in human $\mathrm{CD} 4^{+}$lymphoblasts, ${ }^{57}$ that affects CCR5 ligand ability and impairs the activation of cell signaling. Notably, even though the majority of CCR5 resides within raft microdomains, the receptor can function in nonraft domain as it happens for HIV entry into the cell. ${ }^{58}$ Other studies have also suggested the contribution of the caveolar network during the internalization of GCPRs. For example, by using a labeled cholera toxin bound to ganglioside GM1, it has been shown the direct contribution of caveolae and caveolin-1 during the endocytosis of the adenosine receptor
A1 in smooth muscle cells. ${ }^{59}$ Based on the role of adenosine during ischemia and inflammation and the expression of adenosine receptors in $\mathrm{EC}^{60}$ the caveolar network may represent a potential target in the treatment of damaged tissues. In addition, other GCPRs such as the endothelin type A (ETAR) and B (ETBR) receptors were found localized into LRs/caveolae in rat peritubular smooth muscle cells. ${ }^{61}$ To this regard, these authors demonstrated that the integrity of these plasma membrane microdomains is essential only for ETBbut not for ETA-mediated $\mathrm{Ca}^{2+}$ signaling, emphasizing the role of caveolae during the spatio-temporal coordination of NAADP (Nicotinic acid adenine dinucleotide phosphate)dependent $\mathrm{Ca}^{2+}$ release through ETBRs. Other authors reported that, in EC, only ETBR resides within caveolae from which it is internalized upon administration of endothelin. These observations were supported by the use of specific ETBR (but not ETAR) inhibitors that prevented ET-induced budding of caveolae. ${ }^{62}$ RTKs represent a large family of molecules also involved in signal transduction. The different types of RTKs are included into about twenty different RTK classes and many of them have been found either localized into caveolae or to interact with caveolin-1. ${ }^{63}$ ${ }^{67}$ In addition, vascular endothelial growth factor (VEGF), angiopoietin, PDGF and Ephrin receptors, all belonging to the RTK family, have been found mostly expressed in EC where they play a central role during the angiogenic process. ${ }^{68}$ There is no much information regarding the contribution of the caveolae network during ligand-gated ion channels signaling specifically in the endothelium. However, it has been reported the compartmentalization of $\mathrm{P} 2 \times 7 \mathrm{R}$ into caveolae and its colocalization with caveolin- $1^{69}$ in EC, even though the significance of this interaction is far from being elucidated.

\section{CAVEOLAE AND CAVEOLINS IN ENDOTHELIAL CELLS}

The generation of caveolin null mice made it possible to investigate more in deep the significance and the contribution of both the caveolar system and caveolins to the animal physiology. ${ }^{70-73}$ In cultured EC, caveolin-1 functions as a major scaffolding protein that helps to sequestrate key signaling molecules, such as TNFR1 and TNF-alpha converting enzyme (TACE), into caveolae. ${ }^{64,74-76}$ During the past two decades, the study of caveolae and caveolin proteins has generated great attention especially because of their involvement in pathological conditions. ${ }^{77,78}$ Caveolins, and in particular caveolin-1, have been involved in a variety of different cellular mechanisms from membrane trafficking to cell migration, angiogenesis, and cancer. Besides adipocytes, where caveolae are particularly abundant, EC show an overall high number of caveolae, mostly observed in the microvascular continuous endothelium, but excluded in 
fenestrated endothelium, and sinusoids. ${ }^{79}$ The high abundance of caveolae in EC has further stimulated the investigation of these organelles in EC biology, originally started with the studies of Palade and Bruns in the vascular endothelium in the late $60 \mathrm{~s} .{ }^{80,81} \mathrm{~A}$ variety of caveolin-1 containing vesicles are usually found in EC and, in addition to characteristic non-coated flask invaginations of the plasma membrane, endothelia appear to contain different caveolin-1 positive structures such as tubular channels or floating vesicles detached from the plasma membrane. ${ }^{18}$ In addition to their role in trafficking of molecules across the endothelial barrier, caveolae, and caveolins can function as mechanoreceptors during EC response to extracellular hemodynamic forces such as the shear stress. Indeed, the endothelium does not exclusively function as a physical barrier between blood and the blood vessel wall but it is normally exposed to hemodynamics forces of different amplitude that can contribute to the development of vascular conditions such as inflammation and atherosclerosis. Therefore, EC have developed the ability to convert these mechanical cues into precise signal transduction mechanisms. Several molecular receptors have been proposed to play an active role during response to mechanical and hemodynamic forces in EC. These include integrins, VEGFR2, GPCRs and purinergic receptors. ${ }^{82-85}$ It has been reported that the exposure of EC to shear stress or stretch, affects the number as well as the distribution of caveolae ${ }^{86,87}$ indicating that these organelles may play a crucial role during EC dysfunctions. ${ }^{88}$ Notably, the number of caveolae, but not necessarily the level of caveolin-1, decreases in primary EC, forcing researchers to employ EC lines that maintain unvaried levels of both caveolae and caveolin- $1 .{ }^{75}$ These observations are also in accordance with recent findings indicating that caveolin-1 deficient cells undergo premature senescence in fibroblasts due to mitochondrial dysfunction. ${ }^{89}$ Since their first description, significant advances have been made in the understanding of the role of the caveolar network in EC functions and the discovery of the caveolin family of proteins has further fostered the investigation of the involvement of the caveolar network both in physiological and pathological models.

\section{5 | CAVEOLIN AS A NEGATIVE REGULATOR OF ENOS ACTIVITY}

Undoubtedly, one of the best-known function that links caveolin-1 to EC functions refers to the ability of this scaffolding protein to inhibit the activity of endothelial nitric oxide (eNOS).${ }^{90,91}$ eNOS was among one of the first proteins found associated to caveolae ${ }^{92}$ where it binds to the caveolin scaffolding domain (CSD, aa 82-101) and to a lesser extent to the C-terminal region (aa 135-178) ${ }^{93}$ of caveolin-1. Following myristoylation of its $\mathrm{N}$-terminal glycine and palmitoylation of the Cys15 and Cys26 residues, eNOS is kept inactive into caveolae, associated to caveolin-1. Only in the presence of specific stimuli this interaction is lost, activating downstream signaling (Figure 1). In addition, the interaction between caveolin-1 and eNOS takes place into caveolae but not into LRs, demonstrating the distinct spatial regulation of caveolaeand rafts-dependent signaling. ${ }^{94}$ In vivo studies confirmed the correlation between the loss of caveolin-1, the increased level of $\mathrm{NO}$ and the decreased arterial myogenic tone in $\mathrm{KO}$ mice, predicting a direct involvement of caveolin-1 in the control of blood pressure. However, whether caveolin-1 depletion is beneficial to control blood pressure is still controversial and only few studies demonstrated a decrease of systemic blood pressure in caveolin-1 KO mice. ${ }^{70,95-97}$ These conflicting results may be explained by the activation of compensatory mechanisms in response to chronic production of $\mathrm{NO}$ in caveolin-1 KO mice, that are hard to investigate. However, the use of cavnoxin, a cell-permeable peptide bearing a specific mutation that disrupts the interaction between eNOS and caveolin- $1,{ }^{98}$ both lowered blood pressure and reduced the myogenic tone in vivo. Based on the relationship that links eNOS to calmodulin activation, both caveolae and caveolin-1 have been proposed as potential candidates involved in
(A)

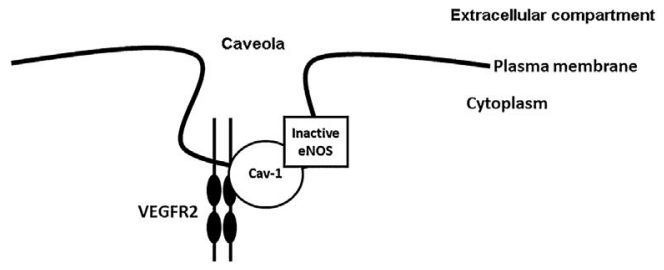

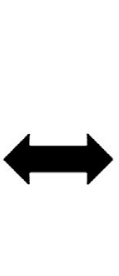

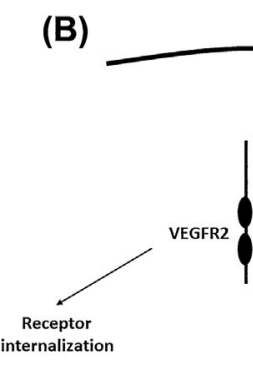

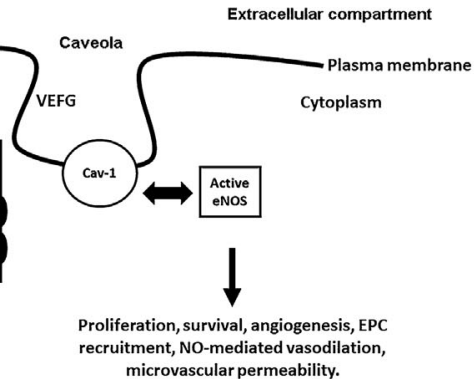

FIGURE 1 Contribution of caveolin-1 to eNOS and VEGFR2 activity. A, in non-stimulated cells, binding of caveolin-1 to eNOS into caveolae, keeps the enzyme in its inactive form. In the same compartment caveolin-1 binds to and sequestrate VEGFR2. B, In the presence of specific stimuli (eg VEGF) binding between caveolin-1 with eNOS or VEGFR2 is lost, favoring downstream signaling 
calcium mobilization, both from the extracellular compartment and from internal stores. Notably, calmodulin activates eNOS by displacing its interaction with caveolin-1. Although caveolae have been proposed to be involved in the regulation of intracellular calcium concentration and calcium dependent signal transduction, ${ }^{99}$ and caveolin-1 has been found determinant for calcium entry into the cell, ${ }^{100,101}$ the precise involvement of the caveolar platform in these mechanisms in endothelium will require further studies.

\section{CAVEOLINS AND ENDOTHELIAL PROGENITORS CELLS (EPCS)}

Blood vessel development in the embryo takes place through two specific mechanisms, namely vasculogenesis or the differentiation and growth of blood vessels from mesodermal derived hemangioblasts and angiogenesis, which ensures further development and remodeling of the primitive vascular network. On the other hand, it is now widely accepted that new vessel formation can arise from differentiating EPCs, residing in the bone marrow. ${ }^{102}$ Since their first appearance in the literature, ${ }^{103}$ EPCs contributed to revise the original concept of vasculogenesis as a mechanism that exclusively takes place in the embryo. Differentiation of EPCs can, indeed, occur also in the adult and may represent a key mechanism during reendothelialization and neovascularization after injury as well as adult vasculogenesis. ${ }^{104-107}$ EPCs have been described as cells expressing VEGFR2, CD34 and CD133, although there is still considerable debate regarding their nature. Many groups have focused their attention on the role of EPCs and their potential contribution to therapeutic angiogenesis. ${ }^{108-111}$ Among known molecules involved in postnatal vasculogenesis, Stromal cell-Derived Factor-1 (SDF-1) and VEGF represent crucial molecules during the recruitment of EPCs. ${ }^{112}$ Although highly debated, some evidence suggesting a role of the caveolar network during EPCs recruitment in the bone marrow, have stimulated the investigation of caveolae/caveolins during postnatal vasculogenesis. ${ }^{113,114}$ The recruitment of EPCs from bone marrow to the peripheral blood appears strictly dependent on the expression of VEGFR2, which resides into caveolae, SDF1, and VEGF itself. ${ }^{115}$ The contribution of caveolin-1 to EPCs recruitment has been recently reported in caveolin-deficient mice $\left(\mathrm{Cav}^{-1-}\right)$. This study demonstrated that defect in caveolin-1 expression impairs internalization of CXCR4 receptor induced by SDF-1 therefore affecting the recruitment of EPCs from bone marrow. ${ }^{116}$ Therefore, understanding the involvement of caveolae/caveolin-1 during the recruitment of EPCs can be central for the development of potential therapeutic applications aimed to induce postnatal vasculogenesis. In addition, recent findings have suggested that NAADP-induced calcium mobilization from intracellular stores promotes EPC proliferation, ${ }^{117}$ suggesting a role of NAADP-induced signaling during neovascularization. ${ }^{118}$ Interestingly, this mechanism is strictly linked to the caveolar network and increasing interest has developed concerning the role of caveolae as potential sites for $\mathrm{Ca}^{2+}$ entry. ${ }^{99,119}$ In addition, studies in the literature suggest the existence of two different EPC populations, named early EPCs (eEPCs) and Outgrowth endothelial cells (OECs) that show a different behavior when cultured in vitro. Interestingly, among a number of different markers evaluated, OECs but not eEPCs express high level of caveolin-1 in addition to VE-cadherin and Von Willebrand Factor. ${ }^{106}$ However, whether the high expression of caveolin-1 in OECs has a biological significance is not known. Nevertheless, since OECs, rather than eEPCs, look more similar to EC and possess intrinsic angiogenic features, they are potential candidates for developing specific therapies for vascular based diseases. Notably, the inhibitory function of caveolin-1 seems to correlate with an increasing expression of stem cell markers in different organs of caveolin-1 KO mice, suggesting a role of caveolin-1 in stem cell differentiation. ${ }^{120}$

\section{7 | THE CAVEOLAR NETWORK IN ANGIOGENESIS}

The formation of new capillary blood vessels, termed angiogenesis, is regulated by a precise balance of growth, and inhibitory factors in healthy tissues. Early during embryo development, mesoderm-derived stem cells give rise to hemangioblasts that differentiate into hematopoietic stem cells (the precursors of blood cells), and angioblasts (the precursors of the blood vessels). ${ }^{121}$ The proliferation and differentiation of angioblasts give rise to $\mathrm{EC}$ and endothelial tubes during vasculogenesis. ${ }^{122,123}$ VEGF is among the key factors involved in the differentiation of angioblasts. To this regard, it has been demonstrated that the lack of a single VEGF allele is sufficient to induce severe defects in the development of the cardiovascular system leading to death before birth. A similar scenario was observed following the disruption of the VEGF receptor genes. ${ }^{124,125}$ The subsequent expansion of this primitive vessel network is carried on during angiogenesis occurring as the result of endothelial sprouting and microvascular growth. Recent studies focused on the development of the retinal vasculature have demonstrated that the expression of plexin-D1 mRNA is rapidly downregulated in the central vascular plexus, where sprouting starts, but remains higher in the actively sprouting vessels. These data suggest a dynamic expression as well as an active role of plexin-D1 in the discrimination between tip and stalk cells during vessel growth in response to VEGF. ${ }^{126}$ However, in the adult the scenario changes because post-natal EC are relatively quiescent during adulthood, when physiological 
angiogenesis is mainly limited to few processes such as wound healing, the uterine cycle (menstruation) and during the development of the placenta throughout the course of pregnancy. Therefore, abnormal development of new blood vessels in the postnatal life is often associated to an imbalanced expression between stimulators and inhibitors of vessel growth that can result in an excessive (switched on) or insufficient (switched off) angiogenesis. Many pathological conditions, including ocular diseases, inflammatory disorders, cancer and metastasis are well known examples of switched on angiogenesis, whereas in other conditions such as ischemic heart disease, the angiogenic switch is inadequate, resulting in EC dysfunction. ${ }^{127}$ Angiogenesis typically takes place under hypoxic condition or in the presence of proangiogenic factors such as $\mathrm{VEGF}^{128-130}$ which acts by increasing vascular permeability and promotes EC migration by weakening inter-EC contacts, destabilizing the preexisting vessels. In the presence of angiogenic stimuli, EC secrete and activate many proteolytic factors, such as matrix metalloproteases (MMPs), that induce the release of growth factors normally trapped in the extracellular matrix (ECM), facilitating EC migration, and their further development into new blood vessels during sprouting angiogenesis. The growth of new capillaries requires the presence of a specialized endothelial "tip cell" that drives the outgrowing vessels by extending motile filopodia toward gradients of angiogenic factors. ${ }^{131}$ A second cell type termed "stalk cell," endowed with a high proliferative aptitude, follows the tip cell, and guarantees the elongation as well as the lumenization of the new vessel. The notch signaling mainly contributes to determine which cells will become tip or stalk cells. Basically, VEGF-induced Delta-like-4 (Dll-4) expression by tip cell activates the notch signaling and dampens VEGFR2 expression in stalk cells, reducing their migratory activity, contrary to what happens to tip cells. ${ }^{132,133}$ The final step in the formation of new blood vessels requires their stabilization through the recruitment of periendothelial pericytes and smooth muscle cells. ${ }^{134}$

\subsection{The caveolar network and the angiogenic machinery}

Among the VEGF receptors, VEGFR2, the major player of VEGF-induced angiogenesis, and VEGFR3 have been found localized into caveolae where they interact with caveolin$1{ }^{135-138}$ Interestingly, in EA.hy926 EC line, the silencing of caveolin-1 by RNAi has been demonstrated to affect cell migration, MMPs activity and VEGF-induced angiogenesis in vitro. ${ }^{139}$ In addition, a variety of proteins that participate in VEGF signal have been shown localized into caveolae, ${ }^{75,140,141}$ and other studies demonstrated that both stimulators and inhibitors of angiogenesis affect the expression of caveolins. ${ }^{45,142}$ Angiogenesis activators, such as
VEGF, basic fibroblast growth factor (bFGF), and HGF have been reported to reduce caveolin-1 expression. By contrast, this effect is reversed in the presence of angiogenesis inhibitors such as angiostatin, thalidomide and others. ${ }^{142}$ In addition, in vivo studies have shown that bFGF-induced angiogenesis was strongly compromised in caveolin-1 KO mice, compared to the wild-type mice. ${ }^{143}$ These data support the idea that angiogenic stimuli require the displacement of adaptor molecules from their inhibited status within the caveolar network. The presence of a functional caveolar network has been found paramount during VEGF-induced ERK activation as well as for ensuring endothelial cell migration following the dissociation of VEGFR2 from the inhibitory effect of caveolin- $1{ }^{64}$ More recently, it has been suggested that in EC caveolin-1 contributes to the assembly of a complex IL1 $\beta$-induced proangiogenic molecular platform, consisting of Tumor Necrosis Factor Receptor 6 (TRAF6), p38-MAPK, and MAPK-activated protein kinase 2. Notably, most of these molecules had been already associated with the caveolae network in EC. ${ }^{75,144}$ Unusual angiogenic process takes place during abnormal blood vessel growth in tumors in response to an unconventional concentration of angiogenic factors in the presence of a hypoxic environment. ${ }^{145}$ Tumor vessels commonly show abnormalities such as tortuosity, fragility, lack of pericytes, tendency to bleeding, exudation and elevated expression of VEGF and VEGFR2. ${ }^{146}$ Nonphysiological concentration of oxygen can contribute to the rearrangement of the plasma membrane proteome and of its endocytic activity via caveolin-1 dependent mechanisms. ${ }^{147}$ It is well known, indeed, that the finely regulated endocytic mechanism as well as the expression of endocytosis associated proteins are frequently affected during malignant transformation and can be regulated by oxygen level. ${ }^{148}$ Therefore, caveolin-1 may play a key role in the regulation of endocytosis within the hypoxic environment, making this protein a potential therapeutic target during malignant transformation.

\section{2 | Pro- and anti-angiogenesis function of caveolin}

Because of the compartmentalization of VEGFR2 into caveolae and its association with caveolin-1, the presence of a functional caveolar network appears to be crucial for VEGF-induced signaling, both under physiological and pathological conditions. Supporting this scenario, it is worth to mention that VEGF functions by disrupting the interaction between caveolin-1, and VEGFR2 within caveolae, ${ }^{64}$ leading to the activation of downstream signaling. This endogenous inhibitory function of caveolin-1 results also evident in its ability to regulate cell polarity, directional movement and cell migration of primary EC, a key step during blood vessel growth in 
response to VEGF. These data demonstrate that not only the expression but even the precise distribution of caveolin-1 within the cellular compartment contributes to determine cell polarity and influences cell functions. ${ }^{149}$ Early evidence regarding the pro-angiogenic role of caveolin-1 date back to the early 2000s, when it was demonstrated that antisense oligodeoxynucleotides against caveolin-1 reduced the number of detectable caveolae and suppressed capillarylike tube formation. ${ }^{150}$ Afterwards, Liu et al. demonstrated that the expression of caveolin-1 increased during EC differentiation, reaching its maximum level just before to the formation of capillary-like tubules. Interestingly, when caveolin-1 was overexpressed, tube formation resulted dramatically accelerated. On the contrary, when caveolin1 was downregulated, the number of capillary-like tubules was reduced by 10 - folds and over. ${ }^{151}$ These findings were further proved in vivo, where the neovascularization of caveolin-1 KO mice injected with a matrigel plug supplemented with bFGF was strongly reduced. ${ }^{143}$ More recently Madaro et al $^{139}$ investigated the role of caveolin-1 at morphological and functional level in EC and demonstrated that silencing of caveolin-1 by RNAi not only induced morphological changes of EC but also reduced cell migration and tubulogenesis in response to VEGF. This talent of caveolin-1 to regulate angiogenesis might be associated to the inhibition of eNOS, which is commonly found associated to caveolin-1 in EC. Indeed, studies performed in both caveolin-1 and eNOS KO mice demonstrated the impairment of cell migration, cell sprouting from aortic rings, tube formation and tumor growth. ${ }^{152}$ Nevertheless, in addition to its pro-angiogenic function in EC, both in vitro and in vivo studies support the antiangiogenic role of caveolin-1. For example, studies from Bauer and collaborators demonstrated that VEGFmediated angiogenesis is reduced by $40 \%$ in transgenic mice overexpressing caveolin-1 in endothelium compared with control littermates. ${ }^{55}$ Another study performed using a caveolin-based plasmid delivery corroborates the antiangiogenic effect of caveolin-1 in microvascular density and tumor growth. ${ }^{153}$ These authors demonstrated that VEGFinduced EC migration and tube formation were strongly reduced in cells overexpressing caveolin-1 and similar results were obtained with the inhibitor of eNOS, confirming the key importance of caveolin-1/eNOS interaction in the regulation of $\mathrm{EC}$ functions. Additional findings supporting the inhibitory activity of caveolin during EC functions, come from an in vitro study showing that overexpression of caveolin-1 in HUVEC reduced VEGFinduced activation of p42/44 MAP kinase. ${ }^{154}$ This controversial function of caveolin-1 may be due to different extracellular environments regulating specific cell functions. Therefore, distinct responses to the same cue may activate different signaling pathways, depending on the specific location and distribution of surface receptors (eg inside or outside caveolae). To this regard, it shouldn't be overlooked the fascinating role of caveolae as mechanosensing structures that cells can employ to adapt to particular extracellular conditions. ${ }^{155}$

\section{8 | FUTURE PERSPECTIVES}

Since their discovery more than 50 years ago, caveolae have been linked to many cellular processes from vesicular transport and cholesterol homeostasis to the onset of pathological conditions. The identification of the caveolin gene family in the late 90 s provided researchers an innovative molecular tool to isolate caveolin enriched membranes thus opening new approaches to investigate the role of the caveolar network in cellular functions. This explains why the investigation in this field has greatly boosted over the years. Among the three caveolin proteins, caveolin-1, the main coat protein of caveolae, appears to be the major player involved in a variety of cellular processes mostly via its CSD through which the protein regulates the activity of key signaling molecules. Although the contribution of the caveolar network has been undoubtedly involved in some pathological conditions (Figure 2), the contribution of caveolins to the onset of cancer and tumor angiogenesis remains still controversial. This is mostly due to the great variability among the different kinds of tumors and to the high heterogeneity of tumor microenvironments. Undoubtedly, tumor cells show altered caveolae as well as changes or loss of caveolin expression, a condition that generates atypical cell signaling. In addition to the structural role, endothelial caveolin-1 and caveolae have been shown to play an important role in angiogenesis by regulating the activity of key molecules as well as downstream signaling events. Despite the ever-growing reports of the involvement of

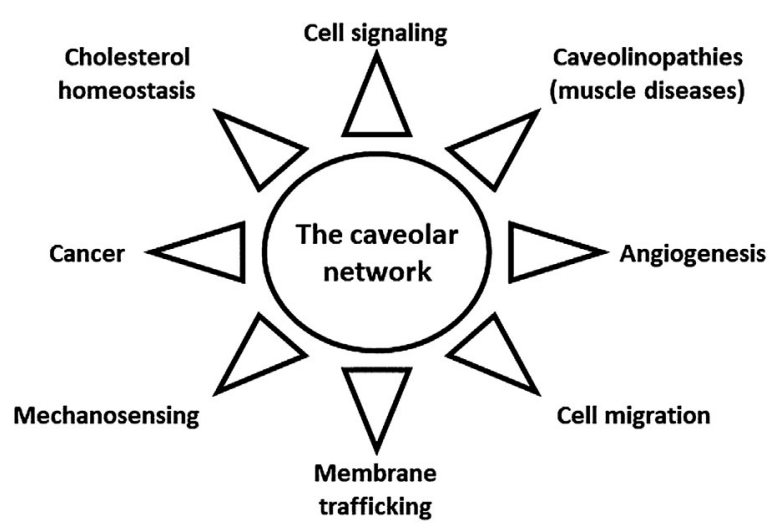

FIGURE 2 Summary of the most common processes regulated by the presence of the caveolar network 
caveolae and caveolins in endothelial cell functions, many aspects concerning their contribution to angiogenesis and angiogenesis based diseases remain open. The generation of caveolin-1 null mice has greatly improved our knowledge of the involvement of the caveolar network in cell functions. However, in most cases the molecular details of disrupted signaling and the intracellular fate of signaling partners in the absence of caveolin-1 remain unclear. Notably, a bioactive secreted form of caveolin-1 has been also reported to regulate cell survival and tumor progression in prostate cancer. ${ }^{149}$ However, the specific role of the soluble form of caveolin-1 in other cell functions, of its trafficking into the extracellular space and its possible interactions with other signaling molecules, represent a potential interest in the field of vascular pathology and tumor angiogenesis. Finally, since the involvement of caveolin-1 in the regulation of the Notch signaling, it is worth investigating more in detail the possible contribution of this protein to the early steps of the angiogenic process that determines, for example, the specification of tip and stalk cells.

\section{CONFLICT OF INTEREST}

The authors declare no conflicts of interest.

\section{ORCID}

Alessio D'Alessio (iD http://orcid.org/0000-0002-3340-2634

\section{REFERENCES}

1. Singer SJ, Nicolson GL. The fluid mosaic model of the structure of cell membranes. Science. 1972;175:720-731.

2. Edidin M. Lipids on the frontier: a century of cell-membrane bilayers. Nat Rev Mol Cell Biol. 2003;4:414-418.

3. Pike LJ. Rafts defined: a report on the keystone symposium on lipid rafts and cell function. J Lipid Res. 2006;47:1597-1598.

4. Gonnord P, Blouin CM, Lamaze C. Membrane trafficking and signaling: two sides of the same coin. Semin Cell Dev Biol. 2012; 23:154-164.

5. Simons K, Ikonen E. Functional rafts in cell membranes. Nature. 1997;387:569-572.

6. Simons K, van Meer G. Lipid sorting in epithelial cells. Biochemistry. 1988;27:6197-6202.

7. Pike LJ. Lipid rafts: bringing order to chaos. Journal of Lipid Research. 2003;44:655-667.

8. Sezgin E, Levental I, Mayor S, Eggeling C. The mystery of membrane organization: composition, regulation and roles of lipid rafts. Nat Rev Mol Cell Biol. 2017;18:361-374.

9. Laurenzana A, Fibbi G, Chillà A, et al. Lipid rafts: integrated platforms for vascular organization offering therapeutic opportunities. Cell Mol Life Sci. 2015;72:1537-1557.

10. Head BP, Insel PA. Do caveolins regulate cells by actions outside of caveolae? Trends Cell Biol. 2007;17:51-57.
11. Palade GE. An electron microscope study of the mitochondrial structure. J Histochem Cytochem. 1953;1:188-211.

12. Yamada E. The fine structure of the gall bladder epithelium of the mouse. J Biophys Biochem Cytol. 1955;1:445-458.

13. Simionescu N. Cellular aspects of transcapillary exchange. Physiol Rev. 1983;63:1536-1579.

14. Fielding PE, Fielding CJ. Plasma membrane caveolae mediate the efflux of cellular free cholesterol. Biochemistry. 1995;34: 14288-14292.

15. Smart EJ, Ying Y, Donzell WC, Anderson RG. A role for caveolin in transport of cholesterol from endoplasmic reticulum to plasma membrane. J Biol Chem. 1996;271:29427-29435.

16. Anderson RG, Kamen BA, Rothberg KG, Lacey SW. Potocytosis: sequestration and transport of small molecules by caveolae. Science. 1992;255:410-411.

17. Schnitzer JE, Oh P, McIntosh DP. Role of GTP hydrolysis in fission of caveolae directly from plasma membranes. Science. 1996;274:239-242.

18. Razani B, Woodman SE, Lisanti MP. Caveolae: from cell biology to animal physiology. Pharmacol Rev. 2002;54:431-467.

19. Glenney JR, Jr., Soppet D. Sequence and expression of caveolin, a protein component of caveolae plasma membrane domains phosphorylated on tyrosine in Rous sarcoma virus-transformed fibroblasts. Proc Natl Acad Sci U S A. 1992;89:10517-10521.

20. Rothberg KG, Heuser JE, Donzell WC, Ying YS, Glenney JR, Anderson RG. Caveolin, a protein component of caveolae membrane coats. Cell. 1992;68:673-682.

21. Kurzchalia TV, Dupree P, Monier S. VIP21-Caveolin, a protein of the trans-Golgi network and caveolae. FEBS Lett. 1994;346: $88-91$.

22. Chang WJ, Ying YS, Rothberg KG, et al. Purification and characterization of smooth muscle cell caveolae. J Cell Biol. 1994;126:127-138.

23. Lisanti MP, Scherer PE, Tang Z, Sargiacomo M. Caveolae, caveolin and caveolin-rich membrane domains: a signaling hypothesis. Trends Cell Biol. 1994;4:231-235.

24. Lisanti MP, Scherer PE, Vidugiriene J, et al. Characterization of caveolin-rich membrane domains isolated from an endothelialrich source: implications for human disease. J Cell Biol. 1994; 126:111-126.

25. Lisanti MP, Tang Z, Scherer PE, Kubler E, Koleske AJ, Sargiacomo M. Caveolae, transmembrane signalling and cellular transformation. Mol Membr Biol. 1995;12:121-124.

26. Sargiacomo M, Sudol M, Tang Z, Lisanti MP. Signal transducing molecules and glycosyl-phosphatidylinositol-linked proteins form a caveolin-rich insoluble complex in MDCK cells. J Cell Biol. 1993;122:789-807.

27. Scherer PE, Lewis RY, Volonte D, et al. Cell-type and tissuespecific expression of caveolin-2. Caveolins 1 and 2 co-localize and form a stable hetero-oligomeric complex in vivo. J Biol Chem. 1997;272:29337-29346.

28. Tang Z, Scherer PE, Okamoto T, et al. Molecular cloning of caveolin-3, a novel member of the caveolin gene family expressed predominantly in muscle. J Biol Chem. 1996;271: 2255-2261.

29. Scherer PE, Okamoto T, Chun M, Nishimoto I, Lodish HF, Lisanti MP. Identification, sequence, and expression of caveolin-2 defines a caveolin gene family. Proc Natl Acad Sci U S A. 1996;93:131-135. 
30. Li S, Galbiati F, Volonte D, et al. Mutational analysis of caveolininduced vesicle formation. Expression of caveolin-1 recruits caveolin-2 to caveolae membranes. FEBS Lett. 1998;434: 127-134.

31. Das K, Lewis RY, Scherer PE, Lisanti MP. The membranespanning domains of caveolins-1 and -2 mediate the formation of caveolin hetero-oligomers. Implications for the assembly of caveolae membranes in vivo. $J$ Biol Chem. 1999;274: 18721-18728.

32. Dietzen DJ, Hastings WR, Lublin DM. Caveolin is palmitoylated on multiple cysteine residues. Palmitoylation is not necessary for localization of caveolin to caveolae. J Biol Chem. 1995;270: 6838-6842.

33. Shenoy-Scaria AM, Dietzen DJ, Kwong J, Link DC, Lublin DM. Cysteine3 of Src family protein tyrosine kinase determines palmitoylation and localization in caveolae. J Cell Biol. 1994;126:353-363.

34. Shaul PW, Smart EJ, Robinson LJ, et al. Acylation targets emdothelial nitric-oxide synthase to plasmalemmal caveolae. J Biol Chem. 1996;271:6518-6522.

35. Busija AR, Patel HH, Insel PA. Caveolins and cavins in the trafficking, maturation, and degradation of caveolae: implications for cell physiology. Am J Physiol Cell Physiol. 2017;312: C459-C477.

36. Hill MM, Bastiani M, Luetterforst R, et al. PTRF-Cavin, a conserved cytoplasmic protein required for caveola formation and function. Cell. 2008;132:113-124.

37. Kovtun O, Tillu VA, Ariotti N, Parton RG, Collins BM. Cavin family proteins and the assembly of caveolae. J Cell Sci. 2015; 128:1269-1278.

38. Ludwig A, Howard G, Mendoza-Topaz C, et al. Molecular composition and ultrastructure of the caveolar coat complex. PLoS Biol. 2005;11:e1001640.

39. Gambin Y, Ariotti N, McMahon KA, et al. Single-molecule analysis reveals self assembly and nanoscale segregation of two distinct cavin subcomplexes on caveolae. Elife. 2014;3:01434.

40. Kovtun O, Tillu VA, Jung W, et al. Structural insights into the organization of the cavin membrane coat complex. Dev Cell. 2014;31:405-419.

41. Grant B, Zhang Y, Paupard MC, Lin SX, Hall DH, Hirsh D. Evidence that RME-1, a conserved C. elegans EH-domain protein, functions in endocytic recycling. Nat Cell Biol. 2001;3:573-579.

42. Lin SX, Grant B, Hirsh D, Maxfield FR. Rme-1 regulates the distribution and function of the endocytic recycling compartment in mammalian cells. Nat Cell Biol. 2001;3:567-572.

43. Hoernke M, Mohan J, Larsson E, et al. EHD2 restrains dynamics of caveolae by an ATP-dependent, membrane-bound, open conformation. Proc Natl Acad Sci U S A. 2017.

44. Anderson RG. The caveolae membrane system. Annu Rev Biochem 1998;67:199-225.

45. Okamoto T, Schlegel A, Scherer PE, Lisanti MP. Caveolins, a family of scaffolding proteins for organizing "preassembled signaling complexes" at the plasma membrane. J Biol Chem. 1998;273:5419-5422.

46. Insel PA, Patel HH. Membrane rafts and caveolae in cardiovascular signaling. Curr Opin Nephrol Hypertens. 2009;18:50-56.

47. Patel HH, Murray F, Insel PA. Caveolae as organizers of pharmacologically relevant signal transduction molecules. Annu Rev Pharmacol Toxicol. 2008;48:359-391.
48. Park DS, Woodman SE, Schubert W, et al. Caveolin-1/3 doubleknockout mice are viable, but lack both muscle and non-muscle caveolae, and develop a severe cardiomyopathic phenotype. Am J Pathol. 2002;160:2207-2217.

49. Sowa G, Pypaert M, Fulton D, Sessa WC. The phosphorylation of caveolin-2 on serines 23 and 36 modulates caveolin-1-dependent caveolae formation. Proc Natl Acad Sci U S A. 2003;100: 6511-6516.

50. Schlegel A, Lisanti MP. A molecular dissection of caveolin-1 membrane attachment and oligomerization. Two separate regions of the caveolin-1 C-terminal domain mediate membrane binding and oligomer/oligomer interactions in vivo. $\mathrm{J}$ Biol Chem. 2000;275:21605-21617.

51. Couet J, Li S, Okamoto T, Ikezu T, Lisanti MP. Identification of peptide and protein ligands for the caveolin-scaffolding domain. Implications for the interaction of caveolin with caveolaeassociated proteins. J Biol Chem. 1997;272:6525-6533.

52. Garcia-Cardena G, Fan R, Stern DF, Liu J, Sessa WC. Endothelial nitric oxide synthase is regulated by tyrosine phosphorylation and interacts with caveolin-1. J Biol Chem. 1996;271:27237-27240.

53. Couet J, Sargiacomo M, Lisanti MP. Interaction of a receptor tyrosine kinase, EGF-R, with caveolins. Caveolin binding negatively regulates tyrosine and serine/threonine kinase activities. J Biol Chem. 1997;272:30429-30438.

54. Engelman JA, Chu C, Lin A, et al. Caveolin-mediated regulation of signaling along the p42/44 MAP kinase cascade in vivo. A role for the caveolin-scaffolding domain. FEBS Lett. 1998;428: 205-211.

55. Bauer PM, Yu J, Chen Y, et al. Endothelial-specific expression of caveolin-1 impairs microvascular permeability and angiogenesis. Proc Natl Acad Sci U S A. 2005;102:204-209.

56. Patel HH, Murray F, Insel PA. G-protein-coupled receptorsignaling components in membrane raft and caveolae microdomains. Handb Exp Pharmacol. 2008;167-184.

57. Nguyen DH, Taub D. Cholesterol is essential for macrophage inflammatory protein 1 beta binding and conformational integrity of CC chemokine receptor 5. Blood. 2002;99:4298-4306.

58. Percherancier Y, Lagane B, Planchenault T, et al. HIV-1 entry into T-cells is not dependent on CD4 and CCR5 localization to sphingolipid-enriched, detergent-resistant, raft membrane domains. J Biol Chem. 2003;278:3153-3161.

59. Escriche M, Burgueno J, Ciruela F, et al. Ligand-induced caveolae-mediated internalization of $\mathrm{A} 1$ adenosine receptors: morphological evidence of endosomal sorting and receptor recycling. Exp Cell Res. 2003;285:72-90.

60. Sands WA, Palmer TM. Adenosine receptors and the control of endothelial cell function in inflammatory disease. Immunol Lett. 2005;101:1-11.

61. Gambara G, Billington RA, Debidda M, et al. NAADP-induced $\mathrm{Ca}(2+)$ signaling in response to endothelin is via the receptor subtype B and requires the integrity of lipid rafts/caveolae. J Cell Physiol. 2008;216:396-404.

62. Oh P, Horner T, Witkiewicz H, Schnitzer JE. Endothelin induces rapid, dynamin-mediated budding of endothelial caveolae rich in ET-B. J Biol Chem. 2012;287:17353-17362.

63. Kabayama K, Sato T, Saito K, et al. Dissociation of the insulin receptor and caveolin-1 complex by ganglioside GM3 in the state of insulin resistance. Proc Natl Acad Sci U S A. 2007;104: 13678-13683. 
64. Labrecque L, Royal I, Surprenant DS, Patterson C, Gingras D, Beliveau R. Regulation of vascular endothelial growth factor receptor-2 activity by caveolin-1 and plasma membrane cholesterol. Mol Biol Cell. 2003;14:334-347.

65. Liao WX, Feng L, Zhang H, Zheng J, Moore TR, Chen DB. Compartmentalizing VEGF-induced ERK2/1 signaling in placental artery endothelial cell caveolae: a paradoxical role of caveolin1 in placental angiogenesis in vitro. Mol Endocrinol. 2009;23: $1428-1444$.

66. Malan D, Elischer A, Hesse M, Wickstrom SA, Fleischmann BK, Bloch W. Deletion of integrin linked kinase in endothelial cells results in defective RTK signaling caused by caveolin 1 mislocalization. Development. 2013;140:987-995.

67. Pike LJ. Growth factor receptors, lipid rafts and caveolae: an evolving story. Biochim Biophys Acta. 2005;1746:260-273.

68. Jeltsch M, Leppanen VM, Saharinen P, Alitalo K. Receptor tyrosine kinase-mediated angiogenesis. Cold Spring Harb Perspect Biol. 2013;5:a009183.

69. Barth K, Pfleger C, Linge A, et al. Increased P $2 \times 7 \mathrm{R}$ expression in atrial cardiomyocytes of caveolin-1 deficient mice. Histochem Cell Biol. 2010;134:31-38.

70. Drab M, Verkade P, Elger M, et al. Loss of caveolae, vascular dysfunction, and pulmonary defects in caveolin-1 gene-disrupted mice. Science. 2001;293:2449-2452.

71. Galbiati F, Volonte D, Engelman JA, et al. Targeted downregulation of caveolin-1 is sufficient to drive cell transformation and hyperactivate the p42/44 MAP kinase cascade. Embo J. 1998;17:6633-6648

72. Razani B, Combs TP, Wang XB, et al. Caveolin-1-deficient mice are lean, resistant to diet-induced obesity, and show hypertriglyceridemia with adipocyte abnormalities. J Biol Chem. 2002; 277:8635-8647.

73. Razani B, Wang XB, Engelman JA, et al. Caveolin-2-deficient mice show evidence of severe pulmonary dysfunction without disruption of caveolae. Mol Cell Biol. 2002;22:2329-2344.

74. D'Alessio A, Al-Lamki RS, Bradley JR, Pober JS. Caveolae participate in tumor necrosis factor receptor 1 signaling and internalization in a human endothelial cell line. Am J Pathol. 2005; 166:1273-1282.

75. D'Alessio A, Kluger MS, Li JH, Al-Lamki R, Bradley JR, Pober JS. Targeting of tumor necrosis factor receptor 1 to low density plasma membrane domains in human endothelial cells. $J$ Biol Chem. 2010;285:23868-23879.

76. D'Alessio A, Esposito B, Giampietri C, Ziparo E, Pober JS, Filippini A. Plasma membrane micro domains regulate TACEdependent TNFR1 shedding in human endothelial cells. J Cell Mol Med. 2011

77. Cohen AW, Hnasko R, Schubert W, Lisanti MP. Role of caveolae and caveolins in health and disease. Physiol Rev. 2004;84: 1341-1379.

78. Gazzerro E, Sotgia F, Bruno C, Lisanti MP, Minetti C. Caveolinopathies: from the biology of caveolin-3 to human diseases. Eur J Hum Genet. 2010;18:137-145.

79. Ogi M, Yokomori H, Oda M, et al. Distribution and localization of caveolin-1 in sinusoidal cells in rat liver. Med Electron Microsc. 2003;36:33-40.

80. Bruns RR, Palade GE. Studies on blood capillaries. I. General organization of blood capillaries in muscle. J Cell Biol. 1968;37: 244-276.
81. Palade GE, Bruns RR. Structural modulations of plasmalemmal vesicles. J Cell Biol. 1968;37:633-649.

82. Jalali S, del Pozo MA, Chen $\mathrm{K}$, et al. Integrin-mediated mechanotransduction requires its dynamic interaction with specific extracellular matrix (ECM) ligands. Proc Natl Acad Sci U S A. 2001;98:1042-1046.

83. Tzima E, Irani-Tehrani M, Kiosses WB, et al. A mechanosensory complex that mediates the endothelial cell response to fluid shear stress. Nature. 2005;437:426-431.

84. Chachisvilis M, Zhang YL, Frangos JA. G protein-coupled receptors sense fluid shear stress in endothelial cells. Proc Natl Acad Sci U S A. 2006;103:15463-15468.

85. Wang Y, Miao H, Li S, et al. Interplay between integrins and FLK1 in shear stress-induced signaling. Am J Physiol Cell Physiol. 2002;283:C1540-C1547.

86. Boyd NL, Park H, Yi H, et al. Chronic shear induces caveolae formation and alters ERK and Akt responses in endothelial cells. Am J Physiol Heart Circ Physiol. 2003;285:H1113-H1122.

87. Sinha B, Koster D, Ruez R, et al. Cells respond to mechanical stress by rapid disassembly of caveolae. Cell. 2010;144:402-413.

88. Davies PF. Hemodynamic shear stress and the endothelium in cardiovascular pathophysiology. Nat Clin Pract Cardiovasc Med. 2009;6:16-26.

89. Allen JA, Yu JZ, Dave RH, Bhatnagar A, Roth BL, Rasenick MM. Caveolin-1 and lipid microdomains regulate Gs trafficking and attenuate Gs/adenylyl cyclase signaling. Mol Pharmacol. 2009;76:1082-1093.

90. Michel JB, Feron O, Sacks D, Michel T. Reciprocal regulation of endothelial nitric-oxide synthase by $\mathrm{Ca} 2+-$ calmodulin and caveolin. J Biol Chem. 1997;272:15583-15586.

91. Bucci M, Gratton JP, Rudic RD, et al. In vivo delivery of the caveolin-1 scaffolding domain inhibits nitric oxide synthesis and reduces inflammation. Nat Med. 2000;6:1362-1367.

92. Feron O, Belhassen L, Kobzik L, Smith TW, Kelly RA, Michel T. Endothelial nitric oxide synthase targeting to caveolae. Specific interactions with caveolin isoforms in cardiac myocytes and endothelial cells. J Biol Chem. 1996;271:22810-22814.

93. Garcia-Cardena G, Martasek P, Masters BS, et al. Dissecting the interaction between nitric oxide synthase (NOS) and caveolin. Functional significance of the nos caveolin binding domain in vivo. J Biol Chem. 1997;272:25437-25440.

94. Sowa G, Pypaert M, Sessa WC. Distinction between signaling mechanisms in lipid rafts vs. caveolae. Proc Natl Acad Sci U S A. 2001;98:14072-14077.

95. Albinsson S, Nordstrom I, Sward K, Hellstrand P. Differential dependence of stretch and shear stress signaling on caveolin-1 in the vascular wall. Am J Physiol Cell Physiol. 2008;294: C271-C279.

96. Rahman A, Sward K. The role of caveolin-1 in cardiovascular regulation. Acta Physiol (Oxf). 2009;195:231-245.

97. Razani B, Engelman JA, Wang XB, et al. Caveolin-1 null mice are viable but show evidence of hyperproliferative and vascular abnormalities. J Biol Chem. 2001;276:38121-38138.

98. Bernatchez P, Sharma A, Bauer PM, Marin E, Sessa WC. A noninhibitory mutant of the caveolin-1 scaffolding domain enhances eNOS-derived NO synthesis and vasodilation in mice. J Clin Invest. 2011;121:3747-3755.

99. Isshiki M, Anderson RG. Calcium signal transduction from caveolae. Cell Calcium. 1999;26:201-208. 
100. Brazer SC, Singh BB, Liu X, Swaim W, Ambudkar IS. Caveolin-1 contributes to assembly of store-operated $\mathrm{Ca} 2+$ influx channels by regulating plasma membrane localization of TRPC1. J Biol Chem. 2003;278:27208-27215.

101. Murata T, Lin MI, Stan RV, Bauer PM, Yu J, Sessa WC. Genetic evidence supporting caveolae microdomain regulation of calcium entry in endothelial cells. J Biol Chem. 2007;282: 16631-16643.

102. Masuda H, Asahara T. Post-natal endothelial progenitor cells for neovascularization in tissue regeneration. Cardiovasc Res. 2003;58:390-398.

103. Asahara T, Murohara T, Sullivan A, et al. Isolation of putative progenitor endothelial cells for angiogenesis. Science. 1997;275:964-967.

104. Rafii S. Circulating endothelial precursors: mystery, reality, and promise. J Clin Invest. 2000;105:17-19.

105. Rafii S, Avecilla S, Shmelkov S, et al. Angiogenic factors reconstitute hematopoiesis by recruiting stem cells from bone marrow microenvironment. Ann N Y Acad Sci. 2003;996:49-60.

106. Medina RJ, O'Neill CL, Sweeney M, et al. Molecular analysis of endothelial progenitor cell (EPC) subtypes reveals two distinct cell populations with different identities. BMC Med Genomics. 2010;3:18.

107. Resch T, Pircher A, Kahler CM, Pratschke J, Hilbe W. Endothelial progenitor cells: current issues on characterization and challenging clinical applications. Stem Cell Rev. 2012;8:926-939.

108. Tateishi-Yuyama E, Matsubara H, Murohara T, et al. Therapeutic angiogenesis for patients with limb ischaemia by autologous transplantation of bone-marrow cells: a pilot study and a randomised controlled trial. Lancet. 2002;360:427-435.

109. Jung KH, Chu K, Lee ST, et al. Circulating endothelial progenitor cells as a pathogenetic marker of moyamoya disease. J Cereb Blood Flow Metab. 2008;28:1795-1803.

110. Sekiguchi H, Ii M, Losordo DW. The relative potency and safety of endothelial progenitor cells and unselected mononuclear cells for recovery from myocardial infarction and ischemia. $J$ Cell Physiol. 2009;219:235-242.

111. Wang R, Chadalavada K, Wilshire J, et al. Glioblastoma stem-like cells give rise to tumour endothelium. Nature. 2010;468:829-833.

112. Losordo DW, Dimmeler S. Therapeutic angiogenesis and vasculogenesis for ischemic disease: part II: cell-based therapies. Circulation. 2004;109:2692-2697.

113. Sbaa E, Dewever J, Martinive P, Bouzin C, Frerart F, Balligand JL, Dessy C, Feron O. Caveolin plays a central role in endothelial progenitor cell mobilization and homing in SDF-1-driven postischemic vasculogenesis. Circ Res. 2006;98:1219-1227.

114. Tan Z, Zhou LJ, Li Y, et al. E(2)-BSA activates caveolin-1 via $\mathrm{PI}(3) \mathrm{K} / \mathrm{ERK} 1 / 2$ and lysosomal degradation pathway and contributes to EPC proliferation. Int J Cardiol. 2012;158:46-53.

115. Losordo DW, Dimmeler S. Therapeutic angiogenesis and vasculogenesis for ischemic disease. Part I: angiogenic cytokines. Circulation. 2004;109:2487-2491.

116. Cheng M, Huang K, Zhou J, et al. A critical role of Src family kinase in SDF-1/CXCR4-mediated bone-marrow progenitor cell recruitment to the ischemic heart. J Mol Cell Cardiol. 2015;81: 49-53.

117. Di Nezza F, Zuccolo E, Poletto V, et al. Liposomes as a putative tool to investigate NAADP signaling in vasculogenesis. $J$ Cell Biochem. 2017.
118. Favia A, Desideri M, Gambara G, et al. VEGF-induced neoangiogenesis is mediated by NAADP and two-pore channel2-dependent Ca2+ signaling. Proc Natl Acad Sci U S A. 2014;111: E4706-E4715.

119. Popescu LM, Diculescu I, Zelck U, Ionescu N. Ultrastructural distribution of calcium in smooth muscle cells of guinea-pig taenia coli. A correlated electron microscopic and quantitative study. Cell Tissue Res. 1974;154:357-378.

120. Sotgia F, Williams TM, Cohen AW, Minetti C, Pestell RG, Lisanti MP. Caveolin-1-deficient mice have an increased mammary stem cell population with upregulation of Wnt/beta-catenin signaling. Cell Cycle. 2005;4:1808-1816.

121. Shalaby F, Ho J, Stanford WL, et al. A requirement for Flk1 in primitive and definitive hematopoiesis and vasculogenesis. Cell. 1997;89:981-990.

122. Risau W. Mechanisms of angiogenesis. Nature. 1997;386: 671-674.

123. Schmidt T, Carmeliet P. Blood-vessel formation: bridges that guide and unite. Nature. 2007;465:697-699.

124. Fong GH, Rossant J, Gertsenstein M, Breitman ML. Role of the Flt-1 receptor tyrosine kinase in regulating the assembly of vascular endothelium. Nature. 1995;376:66-70.

125. Shalaby F, Rossant J, Yamaguchi TP, et al. Failure of blood-island formation and vasculogenesis in Flk-1-deficient mice. Nature. 1995;376:62-66.

126. Kim J, Oh WJ, Gaiano N, Yoshida Y, Gu C. Semaphorin 3EPlexin-D1 signaling regulates VEGF function in developmental angiogenesis via a feedback mechanism. Genes Dev. 2011;25:1399-1411.

127. Carmeliet P. Angiogenesis in life, disease and medicine. Nature. 2005;438:932-936.

128. Ferrara N, Davis-Smyth T. The biology of vascular endothelial growth factor. Endocr Rev. 1997;18:4-25.

129. Ferrara N, Keyt B. Vascular endothelial growth factor: basic biology and clinical implications. Exs. 1997;79:209-232.

130. Ferrara N. Vascular endothelial growth factor and the regulation of angiogenesis. Recent Prog Horm Res. 2000;55:15-35.

131. Lobov IB, Renard RA, Papadopoulos N, et al. Delta-like ligand 4 (Dll4) is induced by VEGF as a negative regulator of angiogenic sprouting. Proc Natl Acad Sci U S A. 2007;104: 3219-3224.

132. Carmeliet P, De Smet F, Loges S, Mazzone M. Branching morphogenesis and antiangiogenesis candidates: tip cells lead the way. Nat Rev Clin Oncol. 2009;6:315-326.

133. Suchting S, Freitas C, le Noble F, et al. The Notch ligand Deltalike 4 negatively regulates endothelial tip cell formation and vessel branching. Proc Natl Acad Sci U S A. 2007;104:3225-3230.

134. Carmeliet P. Mechanisms of angiogenesis and arteriogenesis. Nat Med. 2000;6:389-395.

135. Feng Y, Venema VJ, Venema RC, Tsai N, Caldwell RB. VEGF induces nuclear translocation of Flk-1/KDR, endothelial nitric oxide synthase, and caveolin-1 in vascular endothelial cells. Biochem Biophys Res Commun. 1999;256:192-197.

136. Sonveaux P, Martinive P, DeWever J, et al. Caveolin-1 expression is critical for vascular endothelial growth factor-induced ischemic hindlimb collateralization and nitric oxide-mediated angiogenesis. Circ Res. 2004;95:154-161.

137. Federico G, Francesca A, Ahmad S, Maurizio O, Marina R, Salvatore O. Vascular endothelial growth factor receptor-3 
activity is modulated by its association with caveolin-1 on endothelial membrane. Biochemistry. 2007;46:3998-3905.

138. Thompson TC, Tahir SA, Li L, et al. The role of caveolin-1 in prostate cancer: clinical implications. Prostate Cancer Prostatic Dis. 2009.

139. Madaro L, Antonangeli F, Favia A, et al. Knock down of caveolin1 affects morphological and functional hallmarks of human endothelial cells. J Cell Biochem. 2013;114:1843-1851.

140. Caliceti C, Zambonin L, Rizzo B, et al. Role of plasma membrane caveolae/lipid rafts in VEGF-induced redox signaling in human leukemia cells. Biomed Res Int. 2014;2014:857504.

141. Oshikawa J, Urao N, Kim HW, et al. Extracellular SOD-derived $\mathrm{H} 2 \mathrm{O} 2$ promotes VEGF signaling in caveolae/lipid rafts and postischemic angiogenesis in mice. PLoS ONE. 2010;5:e10189.

142. Liu J, Razani B, Tang S, Terman BI, Ware JA, Lisanti MP. Angiogenesis activators and inhibitors differentially regulate caveolin-1 expression and caveolae formation in vascular endothelial cells. Angiogenesis inhibitors block vascular endothelial growth factor-induced down-regulation of caveolin-1. J Biol Chem. 1999;274:15781-15785.

143. Woodman SE, Ashton AW, Schubert W, et al. Caveolin-1 knockout mice show an impaired angiogenic response to exogenous stimuli. Am J Pathol. 2003;162:2059-2068.

144. Feng X, Gaeta ML, Madge LA, Yang JH, Bradley JR, Pober JS. Caveolin-1 associates with TRAF2 to form a complex that is recruited to tumor necrosis factor receptors. J Biol Chem. 2001;276: 8341-8349.

145. Krock BL, Skuli N, Simon MC. Hypoxia-induced angiogenesis: good and evil. Genes Cancer. 2011;2:1117-1133.

146. Kerbel RS. Tumor angiogenesis. $N$ Engl J Med. 2008;358: 2039-2049.

147. Bourseau-Guilmain E, Menard JA, Lindqvist E, et al. Hypoxia regulates global membrane protein endocytosis through caveolin1 in cancer cells. Nat Commun. 2016;7:11371.
148. Wang Y, Roche O, Yan MS, et al. Regulation of endocytosis via the oxygen-sensing pathway. Nat Med. 2009;15:319-324.

149. Beardsley A, Fang K, Mertz H, Castranova V, Friend S, Liu J. Loss of caveolin-1 polarity impedes endothelial cell polarization and directional movement. J Biol Chem. 2005;280:3541-3547.

150. Griffoni C, Spisni E, Santi S, Riccio M, Guarnieri T, Tomasi V. Knockdown of caveolin-1 by antisense oligonucleotides impairs angiogenesis in vitro and in vivo. Biochem Biophys Res Commun. 2000;276:756-761.

151. Liu J, Wang XB, Park DS, Lisanti MP. Caveolin-1 expression enhances endothelial capillary tubule formation. $J$ Biol Chem. 2002;277:10661-10668.

152. Morais C, Ebrahem Q, Anand-Apte B, Parat MO. Altered angiogenesis in caveolin-1 gene-deficient mice is restored by ablation of endothelial nitric oxide synthase. Am J Pathol. 2012;180:1702-1714.

153. Brouet A, DeWever J, Martinive P, et al. Antitumor effects of in vivo caveolin gene delivery are associated with the inhibition of the proangiogenic and vasodilatory effects of nitric oxide. Faseb $J$. 2005;19:602-604.

154. Fang K, Fu W, Beardsley AR, Sun X, Lisanti MP, Liu J. Overexpression of caveolin-1 inhibits endothelial cell proliferation by arresting the cell cycle at G0/G1 phase. Cell Cycle.2007;6:199-204.

155. Cheng JP, Nichols BJ. Caveolae: one function or many? Trends Cell Biol. 2015;26:177-189.

How to cite this article: Filippini A, Sica G, D'Alessio A. The caveolar membrane system in endothelium: From cell signaling to vascular pathology. J Cell Biochem. 2018;1-12.

https://doi.org/10.1002/jcb.26793 